\title{
Proportion of Human Papilloma Virus in Squamous Epithelial Lesions of Head and Neck- A Polymerase Chain Reaction Study
}

\author{
Bhavya Jayakumar Menon¹, Muthukrishnan Chirayil Ponnappan² \\ ${ }^{1}$ Department of Pathology, Government TD Medical College, Alappuzha, Kerala, India. \\ ${ }^{2}$ Department of Pathology, Government Medical College, Thiruvananthapuram, Kerala, India.
}

\section{ABSTRACT}

\section{BACKGROUND}

Human Papilloma Viruses (HPV) have been implicated to cause 5\% of human cancers. The role of HPV as an etiological agent in the development of precancerous lesions and cancers of head and neck is increasingly being explored. The wide variation in prevalence of HPV has, to some extent, impeded a full understanding of association between HPV and benign and malignant lesions of head and neck. We wanted to determine the proportion of Human Papilloma Virus in squamous epithelial lesions of head and neck using Polymerase Chain Reaction (PCR) studying snap frozen fresh biopsy samples.

\section{METHODS}

This is a descriptive study of cases presenting to the Department of Pathology, Govt. T D Medical College, Alappuzha, Kerala, conducted over a period of one year. 40 cases of clinically suspicious premalignant or malignant squamous lesions of head and neck were biopsied and were subjected to histopathological study and PCR using primer MY11/GP6. Data was entered in Excel sheet. The association of HPV positivity with lesions of head and neck was assessed using SPSS software

\section{RESULTS}

Of the 40 cases studied, the mean age of the cases studied was 55.98 years. Male to female ratio was $29: 11$. Most of the cases were alcoholics $(60 \%)$, with smokers (55\%) and the habit of pan chewing in $20 \%$ of the cases. The histopathological lesions studied were mostly malignant cases (squamous cell carcinoma- $77.5 \%$ of cases) and rest were oral keratosis, vocal cord polyp and a lesion showing chronic inflammation only. The predominant site of biopsy was from oral cavity $(80 \%)$, followed by larynx (16\%) and oropharynx (13\%). HPV positivity was obtained in $2.5 \%$ of the cases, which was not statistically significant. HPV positivity did not show statistically significant association with any of the risk factor behaviours like alcoholism, smoking or pan chewing. The morphological diagnosis associated with HPV was moderately differentiated, which was also not statistically significant.

\section{CONCLUSIONS}

HPV positivity was obtained in $2.5 \%$ of the cases studied with no significant correlation between HPV and squamous epithelial lesions of head and neck.

\section{KEY WORDS}

Human Papilloma Virus, Squamous Cell Carcinoma, Oral Keratosis, Vocal Cord Polyp, Polymerase Chain Reaction
Corresponding Author:

Dr. Muthukrishnan Chirayil Ponnappan, Associate Professor,

Department of Pathology,

Government Medical College,

Thiruvananthapuram, Kerala, India.

E-mail:drmkcp@yahoo.com menon_bhavya@yahoo.com

DOI: 10.14260/jemds/2020/171

Financial or Other Competing Interests: None.

How to Cite This Article:

Menon BJ, Ponnappan MC. Proportion of human papilloma virus in squamous epithelial lesions of head and neck- a polymerase chain reaction study. J. Evolution Med. Dent. Sci. 2020;9(10):786791, DOI: 10.14260/jemds/2020/171

Submission 30-10-2019,

Peer Review 08-02-2020,

Acceptance 14-02-2020,

Published 09-03-2020.

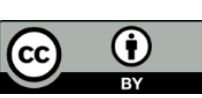




\section{BACKGROUND}

Head and neck cancer is the sixth most common cancer worldwide. The estimated annual burden of the disease worldwide is 563,826 incident cases (including 274,850 oral cavity cancers, 159, 363 larynx cancers, and 52, 100 oropharynx cancers) and 301, 408 deaths.(1) It is the most common cancer in India among males and the fifth most common cancer among females.(2) Recent evidence has recognized Human Papilloma Virus (HPV) as an etiological agent for head and neck cancers.(3) HPV has been found to cause approximately $5 \%$ of human cancers. (4) The Human Papilloma Viruses (HPV) are a heterogenous group of viruses which belong to the family papilloma viridae, with specific tropism to squamous epithelia. HPV are small DNA viruses that infect different epithelial surfaces from anogenital region to head and neck. Some HPV cause benign proliferative lesions like warts or papilloma while a few others act as causative agent in malignant lesions like cervical carcinoma, oral, oropharyngeal, laryngeal carcinomas and skin cancer.(5) Their genome is comprised of episomes of approximately 8000 base pairs (bp) and contain eight open reading frames (ORF).(6) The open reading frames (ORFs) within the genome are divided into early and late genes. 6 genes are located in early region and 2 in late region. The early proteins are regulatory in function and play roles in HPV genome replication and transcription, cell cycle, cell signalling and apoptosis control, immune modulation and structural modification of the infected cell. Throughout the infectious cycle, these proteins are expressed, but they may be reduced in expression in late times. L1 and L2 are the late proteins. They are expressed in the granular layer, which is the outermost layer for mucosal epithelium. When the infected cell differentiates to granular epithelial layer, viral capsid proteins L1 and L2 are expressed and the newly synthesized genome is encapsidated. The newly formed virions are released through mechanical breakage of the cells sloughed off from the upper layer of the epithelium. ${ }^{7}$ )

Human Papilloma Viruses are classified as high risk or low risk HPV.

High risk HPV types - 16,18,31,33,35,49,51,52,56,58,59,66

Low risk HPV types - 6,11,40,42,43,44,54,61,70,72,81,89

HPV 16 and -18 have been found to show malignant transformation of genital and upper aerodigestive tract. Low risk HPV are those that cause benign lesions like warts. HPV is transmitted through skin to skin contact, especially through vaginal, anal or oral sex with a person who has the virus. It can be transmitted even when the infected individual manifests no symptoms or signs of the disease. $(6,7,8)$ HPV16 is the most common subtype to cause Squamous Cell Cancer followed by HPV 18. HPV positive tumours are seen in younger population, approximately 5 years younger by average. The risk is same for both men and women. $(1,2,3)$ HPV positive tumours are commonly seen arising from base of tongue and lingual and palatine tonsils in the oropharynx, compared with other anatomic sites of the head and neck. Histopathologically, HPV positive tumours are usually nonkeratinizing squamous cell carcinoma. They also present at an earlier T stage and more advanced nodal state.(3) There are a few studies which suggest a synergistic effect with tobacco or alcohol whereas a few others have found no such synergy. $(9,10)$ The identification of HPV as a causative agent of head and neck cancers opens up the possibility of using HPV vaccines as an effective strategy in reducing the disease burden.(11) The detection of HPV in premalignant conditions of this anatomical site, suggestive of progressive malignant transformation, also serves as an important point for intervention with vaccination.(12)

There are various techniques for detection of HPV. Diffuse p16 immunopositivity can be used as a surrogate marker for HPV. HPV can also be detected using methods like DNA in situ hybridization, Polymerase chain reaction, electron microscopy or Southern blotting. Of these methods, Polymerase Chain Reaction (PCR) based techniques are widely used. It is highly sensitive and quick and cheap to perform. PCR can generate one billion copies from a single strand of DNA, after 30 cycles of amplification. The segment of DNA which is to be detected is the area flanked by two oligonucleotide sequences. DNA polymerase synthesizes new strands from templates, following denaturation. These new strands will then act as templates for synthesis of new DNA. This results in exponential increase in the amount of DNA from the area of interest. These techniques are highly sensitive and quick and cheap to perform. The yield of false positives due to amplification of contaminant DNA is a potential problem. Careful handling of the DNA samples can help mitigate the problem. The introduction of negative controls in the analysis can also help in resolving the problem. $(3,13)$

We wanted to determine the proportion of Human Papilloma Virus in squamous epithelial lesions of head and neck using Polymerase Chain Reaction studies in snap frozen biopsy samples.

\section{METHODS}

This is a descriptive study with data collected over a duration of one year- from January 2015 to January 2016. Tissue samples of clinically suspicious premalignant or malignant squamous epithelial lesions of head and neck, obtained through biopsies or resection, presenting to the Department of Pathology, Govt T D Medical College, Alappuzha, during the duration of one year, were selected for the study. The patients who received chemotherapy or radiotherapy prior to biopsy or resection were excluded from the study.

\section{Data Collection}

Patient data including name, age, sex, risk factor behaviours, type of surgery, method and site of sampling and relevant past history were collected by direct interview or clinical records from the Departments of Surgery, ENT and OMFS. An informed consent was taken.

\section{Histopathological Examination}

The biopsy specimens sent to the Department of Pathology were properly grossed and fixed in $10 \%$ formalin. The formalin fixed samples were then embedded on paraffin blocks. Routine sections were taken and stained with Haematoxylin and Eosin. The morphology of the lesions was identified using light microscopy. 


\section{Polymerase Chain Reaction Study}

All tissue samples were collected at the time of surgery and snap frozen to $-80^{\circ} \mathrm{C}$. Samples were finely minced with sterile mortar and pestle, washed twice in phosphate buffered saline and pelleted. The samples were then coded. DNA extraction was done using innuPREP DNA mini kit (Analytik Jena, Germany). The ground samples were resuspended in lysis buffer containing proteinase $\mathrm{K}$ and after pulsed vortexing, was incubated at $50^{\circ} \mathrm{C}$ till the lysis was complete. Binding solution was then added followed by vortexing and the sample then applied to spin filter. This was then washed twice by centrifugation at approximately $12000 \mathrm{rpm}$. Elution buffer was added to the spin filter and incubated for one minute at room temperature. This was then centrifuged at $8000 \mathrm{rpm}$ for one minute and the DNA was thus extracted. Specific precautions were taken to prevent and monitor cross contamination during the DNA extraction process. Mucosal PCR primer MY11/GP6 which targets L1 ORF of HPV genome was selected. The size targeted was $190 \mathrm{bp}$. The primer helps in identifying HPV- 16, 18, 31, 33, 6, 11, 32, 72, 26, 66 and 34. Semi nested PCR was performed. Amplifications were performed in $50 \mu \mathrm{L}$ of a reaction mixture containing TaKaRaTaq DNA polymerase (ClonTech, California, USA), 10X PCR Buffer II, $25 \mathrm{mM} \mathrm{MgCl}$, $2.5 \mathrm{mM}$ of each deoxy nucleotide triphosphate and $0.5 \mu \mathrm{L}$ of primer. 30 cycles of PCR were performed $\left(95^{\circ} \mathrm{C}\right.$ for $1 \mathrm{~min}, 50^{\circ} \mathrm{C}$ for $1.5 \mathrm{~min}$ and $72^{\circ} \mathrm{C}$ for 2 min) followed by extension at $72^{\circ} \mathrm{C}$ for 5 minutes. All PCR were performed on a Bio-Rad S1000 thermal cycler. Gel electrophoresis of PCR products was performed and the size of the product band was compared with the expected result of positivity at $190 \mathrm{bp}$. For each PCR amplification, negative controls for reagents and DNA (human placental DNA [Sigma]) were included and processed in the same way as the lesional samples throughout. Negative controls were also kept for DNA extraction procedure. None of the negative controls were positive for HPV.

\section{Statistical Analysis}

The association between HPV positivity and head and neck lesions was observed and the relation between the variables were assessed. The data were entered in Excel sheet and analysed using SPSS software.

\section{RESULTS}

The study included 40 cases of squamous epithelial lesions received in the Department of Pathology. The mean age of the patients was 55.98 (11.757) years with a range of age from 35 to 80 years. Gender based analysis showed mean age for males was 55.34 (10.421) years and for females 57.64 (15.194). Maximum number of patients come under the age group $50-59$ years. $72.5 \%$ of the patients were males and $27.5 \%$ of the patients were females. Of the 40 cases, 24 cases were alcoholics which accounts for $60 \%$ of the cases. $55 \%$ of the cases studied were smokers and only $20 \%$ of the cases studied had the habit of tobacco chewing. The most common site of biopsy was oral cavity (71\%), followed by laryngopharynx $(16 \%)$ and oropharynx (13\%). The most common site of biopsies was from tongue which accounted for $32.3 \%$ of the cases. The 40 cases were examined and the histopathological findings were noted. $77.5 \%$ of the cases were malignant and belonged to the group of squamous cell carcinoma. The rest of the cases (22.5\%) were benign lesions. They were namely oral keratosis, vocal cord polyp and a case of chronic inflammatory lesion. $10 \%$ of the cases were vocal cord polyps. The cases that showed a morphology of squamous cell carcinoma was further classified on the basis of grade. Most of the cases were well differentiated which was calculated as $51.6 \%$ of the total cases. $45.2 \%$ of the cases were moderately differentiated and only $3.2 \%$ of the cases studied were poorly differentiated squamous cell carcinoma. 31 cases of squamous cell carcinoma were observed in the study. $61.3 \%$ of the cases of malignancy showed risk factor behaviour of alcoholism, but the after analysis of association of alcoholism with malignancy, a p value of about 0.525 was obtained (significant $\mathrm{p}$ value $<0.05$ ). $58.1 \%$ of the malignant cases studied showed the habit of smoking. The $p$ value was calculated as 0.324 , whereas significant $p$ value was taken as $\mathrm{p}$ value $<0.05$. Majority of the patients with a histopathological report of squamous cell carcinoma were not in the habit of tobacco chewing. This association showed a $\mathrm{p}$ value of 0.590 . HPV positivity was obtained in $2.5 \%$ of the total patients studied. The proportion of HPV positivity in the cases of malignant squamous lesions accounted for only $3.2 \%$. The gender distribution of the HPV positive cases showed a positivity in only $3.4 \%$ of the total males studied. It showed no association with alcoholism or smoking and an association with tobacco chewing, but none of the $p$ values calculated for risk factor behaviours were significant.

\begin{tabular}{|c|c|c|c|}
\hline Gender & N & Mean & Std. Deviation \\
\hline Male & 29 & 55.34 & 10.421 \\
\hline Female & 11 & 57.64 & 15.194 \\
\hline \multicolumn{3}{|c|}{ Table 1. Mean Age According to Gender in Patients } \\
\hline
\end{tabular}

\begin{tabular}{|c|c|c|}
\hline Sites of HNSCC & No. of Patients & Percentage \\
\hline Tongue & 10 & 32.3 \\
\hline Buccal mucosa & 5 & 16.1 \\
\hline Floor of mouth & 3 & 9.8 \\
\hline Hypopharynx & 3 & 9.8 \\
\hline Alveolar ridge & 2 & 6.4 \\
\hline Soft palate & 2 & 6.4 \\
\hline Hard palate & 2 & 6.4 \\
\hline Tonsil & 1 & 3.2 \\
\hline Vallecula & 1 & 3.2 \\
\hline Epiglottis & 1 & 3.2 \\
\hline Pyriform fossa & $\mathbf{3 1}$ & 3.2 \\
\hline Total & Table 2. Distribution of Cases of Squamous Cell Carcinoma \\
\hline \multicolumn{2}{|c}{ according to Site of Lesion } \\
\hline
\end{tabular}

\begin{tabular}{|c|c|c|}
\hline Squamous Cell Carcinoma & Frequency & Percent \\
\hline Well differentiated & 16 & 51.6 \\
\hline Moderately differentiated & 14 & 45.2 \\
\hline Poorly differentiated & 1 & 3.2 \\
\hline Total & $\mathbf{3 1}$ & $\mathbf{1 0 0 . 0}$ \\
\hline Table 3. Distribution of Cases of Squamous Cell Carcinoma \\
According to Grade \\
\hline
\end{tabular}

\begin{tabular}{|c|c|c|c|c|c|c|c|}
\hline & & & \multicolumn{4}{|c|}{ SCC grade } & \multirow{2}{*}{ Total } \\
\hline & & & $\mathbf{0}$ & 1 & 2 & 3 & \\
\hline \multirow{4}{*}{ HPV } & \multirow[b]{2}{*}{ Positive } & Count & 0 & 0 & 1 & 0 & 1 \\
\hline & & \% within HPV & $.0 \%$ & $.0 \%$ & $100.0 \%$ & $.0 \%$ & $100.0 \%$ \\
\hline & \multirow[b]{2}{*}{ Negative } & Count & 9 & 16 & 13 & 1 & 39 \\
\hline & & \% within HPV & $23.1 \%$ & $41.0 \%$ & $33.3 \%$ & $2.6 \%$ & $100.0 \%$ \\
\hline \multirow{2}{*}{\multicolumn{2}{|c|}{ Total }} & Count & 9 & 16 & 14 & 1 & 40 \\
\hline & & \% within HPV & $22.5 \%$ & $40.0 \%$ & $35.0 \%$ & $2.5 \%$ & $100.0 \%$ \\
\hline \multicolumn{8}{|c|}{$\begin{array}{l}\text { Table 4. Association of HPV Positivity with } \\
\text { Squamous Cell Carcinoma Grade }\end{array}$} \\
\hline
\end{tabular}



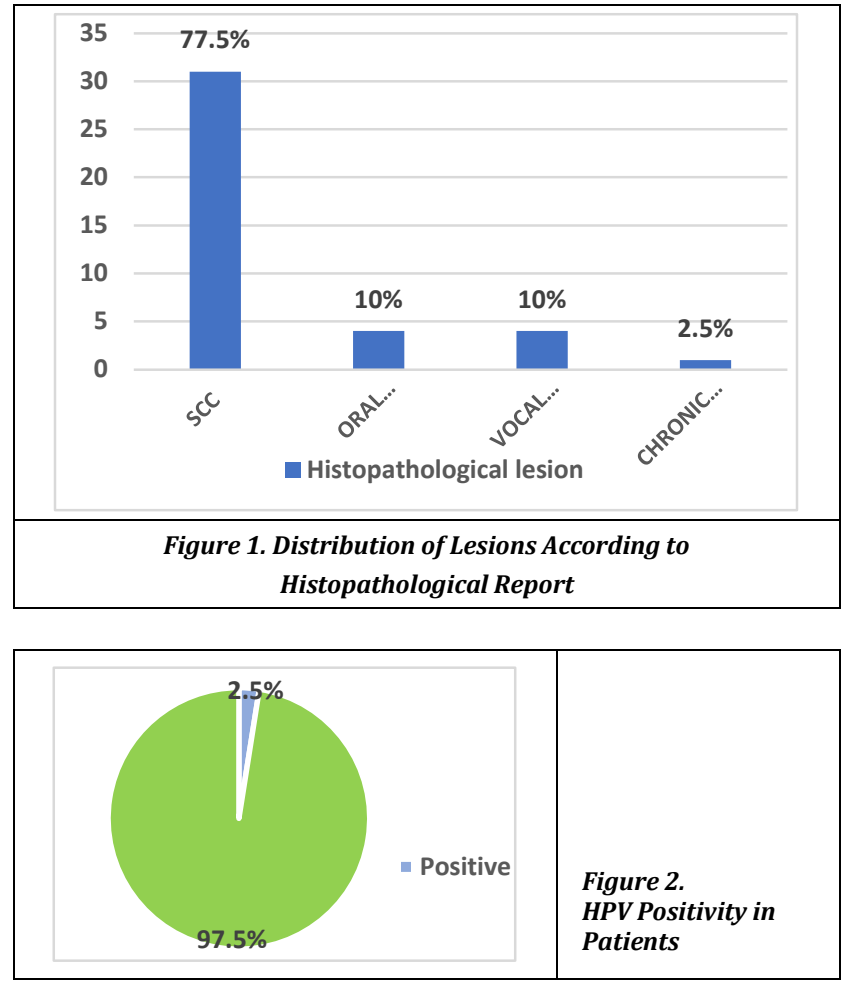

\section{DISCUSSION}

\section{General Characteristics of the Patients}

Head and neck cancers is the sixth most common cancer worldwide. It accounts for $3 \%$ of the total cancer burden. HPV positive cancers are usually seen in present in persons 5 years younger than the usual age. (14) The mean age of the 40 cases in our study was 55.98 (11.757) years with a range of 35 to 80 years. The studies conducted by Hauswald et al from 1995 to 2005(15) and also in another study published in Acta Oncologica in 2012, (16) the mean age is 55 years. $32.5 \%$ of the cases were in the 50-59 age group which accounted for the maximum number of patients in any group. In our study, of the patients with squamous cell carcinoma $67.7 \%$ cases were males and females were $22.3 \%$. This is in accordance with the squamous cell carcinoma statistics published by WHO in 2014. Data published by WHO shows that the incidence of ratio of males to females affected by squamous cell carcinoma ranges from $2: 1$ to $4: 1 .(17)$

\section{Associated Risk Factors and Other Variables}

Among the risk factor behaviours, $60 \%$ of the total cases studied were alcoholics. Malignancy was seen associated with $61.3 \%$ (19) cases with risk factor behaviour of alcoholism. Alcoholism has been accepted as a risk factor for squamous cell carcinoma for a long time with IARC monograph published in 1988 accepting the evidence for human carcinogenic effect of alcoholism. (18) $55.6 \%$ of the total benign cases had risk factor behaviour of alcoholism. Soave et al point out that a relationship between carcinogenic effect of alcoholism and precancerous lesions cannot be definitely made.(19) Of the 40 cases studied, the habit of smoking was found in $55 \%$ of the cases. In our study all the smokers were males and they formed $75.9 \%$ of the males who participated in the study. Schmidt et al in their study regarding tobacco smoking and squamous cell carcinoma found that $69 \%$ of the cases with a history of smoking, had associated squamous cell carcinoma.(20) Of the 40 cases studied, only 8 cases were in the habit of pan chewing. Gupta et al has found a proportion of $37 \%$ cases with pan chewing in Kerala.(21) Pan chewing is a habit spread across South Asia and has been implicated in carcinogenesis. The IARC monograph published in 1984 accepts tobacco chewing as a risk factor for head and neck cancer, especially for oral cavity.(22) In our study $19.4 \%$ of the cases showed association with squamous cell carcinoma.

The histopathological lesions that were included in the study included both benign and malignant lesions. 31 cases of the total were squamous cell carcinoma and 9 were benign lesions. The malignant lesions accounted for $77.5 \%$ of the total cases and benign lesions accounted for $22.5 \%$. Furrer et al studied benign and malignant lesions of head and neck, with $63.7 \%$ cases diagnosed as malignant and $36.3 \%$ of cases classified as benign or potentially malignant. (23) The site of origin of head and neck cancers were classified. The most common site of origin in our study was from oral cavity, with site specified as tongue. The second most common site was buccal mucosa which accounted for $16.1 \%$ of the cases. Broadly, $71 \%$ of the malignancies were biopsies from oral cavity, 16\% from laryngopharynx and 13\% from oropharynx. This is in accordance with the data published by Warnakulasuriya in 2009 about the global epidemiology of cancer.(24) The malignancies were classified according to the morphology and the grade of differentiation was assessed. In our study $51.6 \%$ was well differentiated, $45.2 \%$ was moderately differentiated and $3.2 \%$ was poorly differentiated. In the study conducted by Yun et al, well differentiated squamous cell carcinoma were $63 \%$, moderately differentiated were $18.5 \%$ and poorly differentiated were $18.5 \%$. $^{(25)}$

\section{HPV Positivity and Association with Variable Factors}

In our study HPV positive cases accounted for $2.5 \%$ of the total cases of head and neck lesions using PCR as method of detection. The proportion of HPV positivity in the cases of malignant squamous lesions accounted for only $3.2 \%$. In a systemic review of data worldwide, Kreimer et al found that taking head and neck biopsies as a whole, without reference to site of biopsy, the prevalence of HPV positive cases in malignancies came upto $26 \%$. Kreimer et al used PCR based methods to identify and genotype HPV.(26) In their meta analytical study conducted for a duration of about 20 years, Termine et al gives the prevalence in non-site-specific head and neck squamous cell carcinoma as $24 \%$. Termine et al used both PCR and in situ hybridization as the methods of detection of HPV.(27) Koppikker et al used PCR method to detect HPV in oral malignancies and found out a positivity of only 6\%.(28) Meanwhile Balram et al (29) have found HPV positivity in $74 \%$ of cases of oral squamous cell carcinoma and Wilczynski et al(30) found a prevalence of $64 \%$ HPV positivity. This suggests that there is a wide variability in HPV positivity in head and neck cancers throughout literature. The benign and potentially malignant lesions considered in our study did not show HPV positivity. Fouret et al studied premalignant lesions in their study published in 1995 and found $0 \%$ of cases that showed HPV positivity. (31) In our study HPV positivity was obtained in oropharyngeal case, with lesions from oral cavity and laryngopharynx showed no 
positivity. Kreimer et al have found out that HPV positivity, when classified based on site, showed maximum prevalence in oropharynx (35.6\%).(26) Boscolo-Rizzo et al claim that oropharynx is the only head and neck site with a definite etiological association between HPV infection and development of squamous cell carcinoma.(32) In our study HPV positive case was male who belonged to the 50-59 age group. According to Gillison et al, HPV positive head and neck SCC was detected mostly in males, with $85 \%$ of the positive cases in their study being males. The age group for HPV positive head and neck SCC is lesser than that of HPV negative head and neck SCC. HPV positive head and neck SCC had a mean age of 54 years whereas HPV negative head and neck SCC had a mean age of 58 years in their study.(33,34)

HPV positive case did not show association with alcoholism or smoking in our study. Farshadpour et al (35) concluded in their case control study regarding tobacco and alcohol consumption in HPV associated malignancies that there is no association (12\%) between alcoholism and smoking and HPV positive cancers. Herrero et al (36) have also verified that HPV associated head and neck cancer is seen in non-alcoholic and non-smoker population. In our study the HPV positive case was in the habit of pan chewing. Chen et al had proven that HPV associated malignancies and pan chewing were independent variables. $\left.{ }^{37}\right)$

In our study HPV association was found in a case of malignancy, which showed a morphology of squamous cell carcinoma of moderate differentiation. The morphology of HPV associated malignancy as stated by Marur et al is mostly basaloid. There is also lack of significant keratinization, with lobular growth and unassociated with dysplasia of overlying epithelium.(1,3) None of the benign or premalignant lesions showed any morphology such as koilocytic atypia, suggestive of HPV infection. (38) The method of detection of HPV used in our study is Polymerase Chain Reaction. Abreu et al state that PCR based techniques are highly sensitive, specific and widely used. They also have some disadvantages. This method may show competition for reagents, which lead to false negative results for multiple type infections that are contained in samples at lower copy numbers. (39)

\section{ACKNOWLEDGEMENT}

I would also like to acknowledge the help extended to me by the National Institute of Virology, Alappuzha Unit in doing the PCR studies.

\section{CONCLUSIONS}

There is no significant correlation between HPV and squamous epithelial lesions of head and neck. Considering the wide variability of HPV positivity in the literature, studies with larger sample size are necessary. The method of detection of HPV like PCR has low specificity. Therefore, confirmation of positive cases with genomic sequencing following PCR or specific techniques like in situ hybridization is recommended.

\section{REFERENCES}

[1] Marur S, D'Souza G, Westra WH, et al. HPV-associated head and neck cancer: a virus-related cancer epidemic. The Lancet Oncology 2010;11(8):781-9.

[2] Joshi P, Dutta S, Chaturvedi P, et al. Head and neck cancers in developing countries. Rambam Maimonides Medical Journal 2014;5(2): e0009.

[3] El-Naggar A, Chan JKC, Grandis JR, et al. WHO classification of head and neck tumours. $4^{\text {th }}$ edn. Vol. 9. Lyon: International Aagency for Research on Cancer 2017: p.136-8.

[4] Franco EL, Rohan TE, Villa LL. Epidemiologic evidence and Human Papilloma Virus infection as a necessary cause of cervical cancer. Journal of the National Cancer Institute 1999;91(6):506-11.

[5] Devaraj K, Gillison M, Wu TC. Development of HPV vaccines for HPV-associated head and neck squamous cell carcinoma. Critical Reviews in Oral Biology \& Medicine 2003;14(5):345-62.

[6] Doorbar J, Egawa N, Griffin H, et al. Human papillomavirus molecular biology and disease association. Reviews in Medical Virology 2015;25(Suppl 1):2-23.

[7] Graham SV. Human papillomavirus: gene expression, regulation and prospects for novel diagnostic methods and antiviral therapies. Future Microbiology 2010;5(10):1493-506.

[8] HPV. What is HPV? Human Papillomavirus, CDC. Cdc.gov. 2017 [cited $22 \quad$ October 2017]. https://www.cdc.gov/hpv/parents/whatishpv.html

[9] Smith E, Ritchie J, Summersgill K, et al. Human papillomavirus in oral exfoliated cells and risk of head and neck cancer. Oral Surgery Oral Medicine Oral Pathology Oral Radiology 2003;96(3):301-2.

[10] Herrero R, Castellsague X, Pawlita $M$, et al. Human papillomavirus and oral cancer. The International Agency for Research on Cancer Multicenter Study. J Natl Cancer Inst 2003;95(23):1772-83.

[11] Gillison ML, Chaturvedi AK, Lowy DR. HPV prophylactic vaccines and the potential prevention of non-cervical cancers in both men and women. Cancer 2008;113(S10):3036-46.

[12] Miller CS, White DK. Human papillomavirus expression in oral mucosa, premalignant conditions and squamous cell carcinoma. Oral Surgery Oral Medicine Oral Pathology Oral Radiology 1996;82(1):57-68.

[13] Bryan RL, Bevan IS, Crocker J, et al. Detection of HPV 6 and 11 in tumours of the upper respiratory tract using the polymerase chain reaction. Clinical Otolaryngology Allied Sci 1990;15(2):177-80.

[14] Elrefaey S, Massaro MA, Chiocca S, et al. HPV in oropharyngeal cancer: the basics to know in clinical practice. Acta Otorhinolaryngologica Italica 2014;34(5):299-309.

[15] Hauswald H, Simon C, Hecht S, et al. Long-term outcome and patterns of failure in patients with advanced head and neck cancer. Radiation Oncology 2011;6(1):70. 
[16] Hauswald H, Zwicker F, Rochet N, et al. Treatment of squamous cell carcinoma of the mobile tongue or tongue margins: an interdisciplinary challenge. Acta Oncologica 2013;52(5):1017-21.

[17] http://www.who.int/selection_medicines/committees/e xpert/20/applications/HeadNeck.pdf

[18] IARC Monographs on the evaluation of carcinogenic risks to humans: alcohol drinking. Lyon: International Agency for Research on Cancer, 1988.

[19] Figueiredo D, Celes NM, Oliveira-Costa PJ, et al. The role of Human Papillomavirus in pre-cancerous lesions and oral cancers. Human Papillomavirus and related diseases from bench to bedside: a diagnostic and preventive perspective, 2013.

[20] Schmidt BL, Dierks EJ, Homer L, et al. Tobacco smoking history and presentation of oral squamous cell carcinoma. Journal of Oral and Maxillofacial Surgery 2004;62(9):1055-8.

[21] Gupta PC, Warnakulasuriya S. Global epidemiology of areca nut usage. Addiction Biology 2002;7(1):77-83.

[22] IARC monographs on the evaluation of carcinogenic risks to humans: Tobacco habits other than smoking: Betelquid and Areca-nut chewing: some related nitrosamines. Lyon: International Agency for Research on Cancer Tobacco, 1985.

[23] Furrer V, Benitez $M$, Furnes $M$, et al. Biopsy vs. superficial scraping: detection of human papillomavirus $6,11,16$, and 18 in potentially malignant and malignant oral lesions. Journal of Oral Pathology and Medicine 2006;35(6):338-44.

[24] Warnakulasuriya S. Global epidemiology of oral and oropharyngeal cancer. Oral Oncology 2009;45(4-5):30916.

[25] Yun TJ, Kim JH, Kim KH, et al. Head and neck squamous cell carcinoma: differentiation of histologic grade with standard- and high-b-value diffusion-weighted MRI. Head \& Neck 2012;35(5):626-31.

[26] Kreimer AR, Clifford GM, Boyle P, et al. Human papillomavirus types in head and neck squamous cell carcinomas worldwide: a systematic review. Cancer Epidemiology Biomarkers \& Prevention 2005;14(2):46775.

[27] Termine N, Panzarella V, Falaschini S, et al. HPV in oral squamous cell carcinoma vs head and neck squamous cell carcinoma biopsies: a meta-analysis (1988-2007). Annals of Oncology 2008;19(10):1681-90.

[28] Koppikar P, De Villiiers FM, Mulherkar R. Identification of human papilloma viruses in tumour of the oral cancer in an Indian Community. Int J Cancer 2005;113(6):94650 .
[29] Balaram P, Nalinakumar KR, Abraham E, et al. Human papillomaviruses in 91 oral cancers from Indian betel quid chewers-high prevalence and multiplicity of infections. International Journal of Cancer 1995;61(4):450-4.

[30] Wilczynski SP, Lin BT, Xie Y, et al. Detection of human papillomavirus DNA and oncoprotein overexpression are associated with distinct morphological patterns of tonsillar squamous cell carcinoma. The American Journal of Pathology 1998;152(1):145-56.

[31] Ha PK, Califano JA. The role of Human Papillomavirus in oral carcinogenesis. Critical Reviews in Oral Biology \& Medicine 2004;15(4):188-96.

[32] Boscolo-rizzo P, Del Mistro A, Bussu F, et al. New insights into human papillomavirus-associated head and neck squamous cell carcinoma. Acta Otorhinolaryngologica Italica 2013;33(2):77-87.

[33] Handisurya A, Schellenbacher C, Kirnbauer R. Diseases caused by human papillomaviruses (HPV). Journal Deutschen Dermatologischen Gesellschaft 2009;7(5):453-67.

[34] Gillison M, D'Souza G, Westra W, et al. Distinct risk factor profiles for Human Papillomavirus Type 16-Positive and Human Papillomavirus Type 16-Negative head and neck cancers. JNCI: Journal of the National Cancer Institute 2008;100(6):407-20.

[35] Farshadpour F, Konings S, Speel EJM, et al. Human Papillomavirus and oropharyngeal squamous cell carcinoma: a case-control study regarding tobacco and alcohol consumption. Article ID 806345, Pathology Research International 2011;2011:1-9.

[36] Herrero R, Castellsagué X, Pawlita M, et al. Human papillomavirus and oral cancer: The International Agency for Research on Cancer Multicenter Study. Journal of the National Cancer Institute 2003;95(23):1772-83.

[37] Chen P, Kuo C, Pan C, et al. Risk of oral cancer associated with human papillomavirus infection, betel quid chewing, and cigarette smoking in Taiwan - an integrated molecular and epidemiological study of 58 cases. Journal of Oral Pathology and Medicine 2002;31(6):317-22.

[38] Woo SB, Cashman EC, Lerman MA. Human papillomavirus-associated oral intraepithelial neoplasia. Modern Pathology 2013;26(10):1288-97.

[39] Abreu ALP, Souza RP, Gimenes F, et al. A review of methods for detect human Papillomavirus infection. Virology Journal 2012;9(1):262. 